\title{
Kültürel Öğeler İçeren Reklamların Beğenisi Demografik Özelliklere Göre Farklılaşır Mı?

\author{
(Does, Likes of Advertisements Containing Cultural Elements, Different According to
} Demographic Characteristic?)
}

\author{
Gökhan Alper FIGEN iD a Aslıhan TÜFEKÇi ${ }^{\text {iD }}$ b Metehan TOLON ${ }^{\text {iD }}$ b \\ a Ordu Üniversitesi, Ordu, Türkiye, gokhanalper@gmail.com \\ b Gazi Üniversitesi, Ankara, Türkiye, asli@gazi.edu.tr \\ cAnkara Hacı Bayramı Veli Üniversitesi, Ankara, Türkiye, metehan.tolon@hbv.edu.tr
}

\begin{tabular}{l} 
MAKALE BİLGísí \\
\hline Anahtar Kelimeler: \\
Nöropazarlama \\
Frontal alfa asimetri \\
EEG \\
Kültürel öğeler \\
Video reklamlar
\end{tabular}

Gönderilme Tarihi 3 Temmuz 2021

Revizyon Tarihi 19 Eylül 2021

Kabul Tarihi 27 Eylül 2021

Makale Kategorisi: Araştırma Makalesi

\section{ÖZET}

Amaç - Bu çalışmanın amacı, Türkiye'de doğup büyümüş aynı kültürü paylaşan, katılımcıların demografik özelliklerine göre, kültürel öğeler içeren video reklamlara karşı beğeni (pozitif motivasyonhoşlanma) duygusunun farklılaşmasını incelemektir.

Yöntem - Araştırmanın deney aşaması uygun örnekleme ile seçilmiş 77 (29K+48E) katılımcı ile gerçekleştirilmiştir. Deneyde veri toplama aracı olarak reklam uyaranlarına karşı katılımcıların EEG(elektroensefalografi) ile beyin sinyalleri toplanmış ve frontal alfa $(8-13 \mathrm{~Hz})$ asimetri yöntemi kullanılarak katılımcıların beğeni seviyeleri ölçümlenmiştir. Katılımcıların demografik bilgileri ve ölçek doğrultusunda beyan ettikleri beğeni puanları form ile toplanmıştır. Verilerden SPSS programı aracilığıla ilişkisiz T-testi, Kruskal Wallis H-testi ve Pearson Korelasyon analizleri yapılarak bulgular elde edilmiştir.

Bulgular - Çalışmada kültürel öğeler içeren video reklamlarının, aynı kültürde büyümüş bireylerde olumlu izlenim bıraktığını görülmüştür. Kadınların erkeklere göre beğeni düzeylerinin daha yüksek olduğu görülmüştür. Anaerkil olarak yetişen bireylerin, ataerkil yetişenlere göre beğeni seviyeleri anlamlı şekilde farklılaşmaktadır. Eğitim düzeyinin, medeni halin ve çocukluğun geçtiği yerin ise beğeni seviyesinde anlamlı farklılaşmadığı görülmüştür. Bulgulardan faydalanarak, kadın ve anaerkil ortamda yetişen bireylerin kültürel öğelere karşı beğeni puanını arttırdığı görülmüştür. Diğer bulgu ise EEG beğeni puanı ile beyan beğeni puanı arasında anlamlı bir ilişkinin bulunmamasıdır.

Tartışma - Gerçekleştirilen araştırmada kültür öğelerinin reklamlarda kullanılmasının beğeni duygusu yarattığı görülmüş̧ür. Ayrıca kadınlarda veya anaerkil ortamda yetişen bireyler üzerinde daha etkin bir duygulanım oluşturduğu görülmüştür. Bu çalışma, reklam tasarımcıları ve pazarlamacılar için reklamlarda kullanılacak kültürel öğelerin hedef tüketici grubuna göre vurgulanması gerektiğini göstermiştir. Diğer sonuç ise kişilerin beğeni durumları hakkındaki beyanlarının gerçeği yansıtmadığının görülmüş olmasıdır. Bu durum nöropazarlama araçlarının bireyin tercih ve kararlarını objektif olarak ortaya koymadığı durumlarda etkin bir pazarlama araştırma aracı olduğunu göstermektedir.

\begin{tabular}{ll}
\hline ARTICLE INFO & ABSTRACT \\
\hline Keywords: & $\begin{array}{l}\text { Purpose - The aim of this study is to examine the differentiation of the sense of like (positive motivation- } \\
\text { pleasantness) toward video advertisements containing cultural elements, according to the demographic } \\
\text { characteristics of the participants, who were born and raised in Turkey and share the same culture. } \\
\text { Neuromarketing } \\
\text { Frontal alpha asymmetry }\end{array}$ \\
$\begin{array}{l}\text { DEG } \\
\text { Cultural elements }\end{array}$ & $\begin{array}{l}\text { (29F+48M) participants selected by convenient sampling. As a data collection tool in the experiment, the } \\
\text { bideo ads }\end{array}$ \\
$\begin{array}{l}\text { stimuli and the level of like of the participants was measured using the frontal alpha (8-13 Hz) asymmetry } \\
\text { method. The demographic information of the participants and the like scores they declared in line with } \\
\text { the scale were collected with the form. Findings were obtained by performing independent T-test, Kruskal } \\
\text { Revised 19 September 2021 } \\
\text { Accepted 27 September 2021 }\end{array}$ & Wallis H-test and Pearson Correlation analyzes from the data using the SPSS program.
\end{tabular}

Findings - As a result of the study, it was seen that video ads containing cultural elements left a positive impression on individuals who grew up in the same culture. It was observed that women's level of like score was higher than men's. The level of like of individuals raised as a matriarch differs significantly compared to those raised in a patriarchal manner. It was observed that the level of education, marital status and the place of childhood did not differ significantly in the level of like. By making use of the findings, it was seen that women and grew up in a matriarchal environment increased their like for 
cultural elements. The other finding is that there is no significant relationship between EEG like score and declaration like score.

Discussion - In the research carried out, it was seen that the use of cultural elements in advertisements creates a sense of like. In addition, it has been observed that it creates a more effective affect on women and on grow up in a matriarchal environment. This study showed that the cultural elements to be used in advertisements should be emphasized according to the target consumer group for advertising designers and marketers. The other result is that it has been seen that the statements of people about their likes do not reflect the truth. This shows that neuromarketing tools are an effective marketing research tool when they do not objectively reveal the preferences and decisions of the individual.

\section{Giriş}

İnsanların olaylar karşısında çekinme, korkma, heyecanlanma, dikkatini çekme ya da ilgisizlik gibi duygulanımlarını ve davranışlarını çözümleme ihtiyacı birçok alan için önemli problemlerden biri olmuştur. İnsan davranışları, makine gibi girdileri ile elde edilen çıktıları arasında bir rasyonaliteye oturtulamamaktadır. İnsanların davranışları ve duygulanımları çoğunlukla anket ve söze dayalı beyan gibi veri toplama araçlarıyla ölçülmeye çalışılmaktadır. Fakat etik değerler, otokontrol ve toplum baskısı gibi gerekçelerden dolayı bu verileri yeterince açık ve doğru şekilde toplamak mümkün olmamaktadır (Batı \& Erdem, 2015:15). İnsanların anket, odak grup çalışması, sözlü mülakat, röportaj veri toplama araçlarıyla toplanan verilerinde gerçek düşüncelerini saklama eğiliminde olduğu gözlemlenmiştir (Özkara, 2017:1; Vecchiato et al., 2011:580). Bu bağlamda, insanın sosyal davranışlarına bağlantı veren, bireylerin vücutlarından toplanabilecek fizyolojik sinyallerin analizi ve yorumu ile daha tutarlı ve nitelikli bilgiler elde edilebileceği fikri ön plana çıkmıştır. Bu durum nöropazarlama kavramını doğurmuştur. Nöropazarlama, nörobilimden faydalanarak ürün ve hizmetler karşısında tüketici davranışları ve tercihlerini anlamaya çalışan genç bir disiplindir(Bočková et al., 2021:44; Khurana et al., 2021:2).Tüketicilerin video reklamlar, afişler, müzikler ya da koku gibi uyaranlara karşı duygulanımlarını gözlemlemek (Ortony \& Turner, 1990; Smith et al., 2017; Vecchiato et al., 2013; Vecchiato \& Babiloni, 2011) veya satın alma kararlarını incelemek için beyin görüntüleme ve analiz teknikleri kullanmaktadır (Braeutigam et al., 2004:294; Ozkara \& Bagozzi, 2021:4). Dünyada reklam ve tanıtımlar için yaklaşık 400 milyar dolarlık bir pazar olduğu ve bu pazarın büyümekte olduğu bilinmektedir. Bundan dolayı nöropazarlama alanında keşfedilebilecek yeni bulgular ve iyileştirmeler alana büyük katkılar sağlama potansiyelini ortaya çıkarmaktadır(Khurana et al., 2021:1).

Nöropazarlama çalışmaları bu çerçevede bilgisayar, elektronik, biyoloji, fizik, psikoloji, pazarlama gibi bilimlerin birleşiminden oluşan multidisipliner bir alandır. Bu alanda insanın duygu temeli üzerinde yapılan çalışmalar psiko-fizyolojik odaktan mühendislik uygulamalarına doğru bir eğilim göstermiştir. Duygu tanımlamaları konusunda yaşanan sorunları çözmek için birçok araç ve algoritma geliştirilmiştir (Lakhan et al., 2019). Bu noktada nöropazarlama, nöro görüntüleme teknikleri sayesinde bireyin davranışsal ve duygusal eğilimlerinin gözlemlenmesine olanak vermektedir. Bu da firmalara, tüketicilerin satın alma tercihlerinde nelerden etkilendiğine dair ipuçları vermektedir (Eser et al., 2011:855).

Davranış ve tutumların oluşmasında değerler belirleyici rol oynamaktadır. Bireyin değerlerinin oluşmasında ise toplumun değerler yapısının etkinliği görülmektedir. Bir toplumun geçerli değer yargıları kültürün en temel özelliğini oluşturmaktadır. Kültür bu noktada toplumun "anlam sistemleri"nin paylaşımı olarak tanımlanabilir (de Mooij, 2015:647).

Matsumoto ve Hwang'a (2012:92)göre duyguların oluşumunda doğuştan gelen biyolojik ve bireyin sonradan büyüdüğü toplum içerisinde kazandığı kültürel etkiler yer almaktadır. Biyolojik olarak ele alınan duygularda insanın doğuştan gelen evrensel tepkileri göze çarparken, kültürel etki altında oluşan duygularda ise coğrafyadan coğrafyaya ve toplumdan topluma değişkenlik gösteren tepkiler göze çarpmaktadır. Bununla birlikte duyguların oluşumunda bu iki kavramı birbirinden ayrıştırarak değil, durum ve şartlara göre, duygu içerisinde değişken ağırlıkta olduğu bir bio-kültürel modeli öne sürmüştür. Kültür, duyguların oluşumunda önemli bir katman olarak dikkat çekmektedir (Lim, 2016:2). Estetik, beğeni ve güzellik gibi değerlerin doğuştan gelip gelmediğini merak eden araştırmacılar 6 aylık bebeklere Mozart bestelerinin uyumlu ve uyumsuz notalardan oluşmuş versiyonlarını karışık sırayla dinletmiştir. Elde edilen sonuçlara göre bebekler ilk olarak dinletilen versiyonu daha uzun süre dinlediklerini ve tekrar dinletilmesi durumunda ilk dinlediklerine ilgi duydukları gözlemlenmiştir. Burada beğeni ve estetik için önemli olan notaların uyumlu 


\section{G. A. Figen - A. Tüfekçi - M. Tolon 13/3 (2021) 2819-2831}

ya da uyumsuz olmasından daha çok tecrübeden kaynaklandığı görülmektedir. Bu durum kültür kavramının, duygulanımlarımız için ne denli önemli olduğunu göstermektedir (Plantinga \& Trehub, 2014:47).

Araştırmacılar evrimsel olarak duygu oluşumunun insanı hayatta tutmaya ve insanın çevresine uyum sağlamasına yardımcı olduğunu savunmaktadır. Çünkü duygular, insanlara içinde bulunduğu duruma göre hızlı bilgi sağlayarak, asgari bilinçli düşünmeyle, bilişsel bir tepki üretmeyi sağlamaktadır. Duygular insanın en önemli dünyayı anlamlandırma araçlarından biridir. Karar mekanizmasının tetiklenmesinde de önemli bir rol oynamaktadır (Tooby \& Cosmides, 2008:116). Duygularımız aracılığı ile anılarımızı yapılandırır, düşüncelerimizi temellendirir ve seçimlerimizi gerçekleştirdiğimiz karar mekanizmasında kullanırız (Damasio, 1994; Erdemir \& Yavuz, 2016:25). Reklam çalışmalarında da tüketici üzerinde etki bırakmak için duygu çekiciliğinden yararlanır. Mizah, hüzün, korku, cinsellik çekiciliği gibi duyguları uyaran ve tüketici tarafından marka, ürün ya da hizmetin akılda kalıcılığını artıran çekicilikler kullanılır(Jovanovic et al., 2016:81). Aynı zamanda kültür değerleri ile duygusal çekicilik arasında bir bağlantı mevcuttur. Kişiler kültürel öğeler içeren uyaranlar karşısında duygulanımlarının tetiklendiği görülmüştür(Raza et al., 2018:65).

Araştırmacılar, reklamlarda görsellerin ve kelimelerin anlamları açısından var olduğu kültür ile bir bağlılığının olması gerektiğini söylemektedir. Ayrıca reklamların ikna edici olabilmesi için kültürel uyumluluk olması, yani hedef grubun kültürel değerlerini yansıtması gerekmektedir (Czarnecka et al., 2018:11). Bir yaratının toplumda değer görebilmesi kendinden önce gelen değerlere bağlıdır. Bir başka ifadeyle ortaya konan yeni değerlerin kabul görebilmesi için bile kültür ile bir bağının olması gerekmektedir (Eagleman \& Brandt, 2017:155).

Nöropazarlama alanındaki kültür ve duygu ile ilgili yapılan çalışmalarda genellikle video reklam, afiş, müzik, metin gibi uyaranlara karşı kültürler arası katılımcıların verdiği duygusal tepkiler arasındaki farklılıklar ölçümlenmeye ve anlamlandırılmaya çalışılmıştır (Czarnecka et al., 2018; de Mooij, 2015; Lim, 2016; Matsumoto \& Hwang, 2012). Kültür kavramı içerisinde de bireylerin uyaranlara karşı tepkilerin cinsiyet, yaş, eğitim, otorite gibi demografik özelliklere göre değişkenlik gösterdiği görülmektedir(Rampersad \& Althiyabi, 2020). Bu çalışmanın amacı, Türkiye'de doğup büyümüş aynı kültürü paylaşan, katılımcıların kültürel öğeler içeren video reklamlara karşı beğeni-hoşlanma(pozitif motivasyon) duygusal tepkileri incelenerek bireylerin demografik özelliklerinin beğeni puanı üzerindeki etkisinin incelenmesidir. Bu ana amaç altında cevaplanacak araştırma soruları şunlardır:

1. Katılımcıların beğeni puanları demografik özelliklere (cinsiyet, medeni durum, evdeki baskın karakter, eğitim düzeyi ve çocukluğun geçtiği yer) göre farklılaşmakta mıdır?

2. Katılımcıların EEG cihazı ile ölçülen beğeni puanları demografik özelliklere göre farklılaşan değişkenlerden (cinsiyet ve evdeki baskın karakter) oluşturulan ikili gözenekleri arasında anlamlı bir fark midir?

3. Katılımcıların EEG cihazı ile ölçülen beğeni puanları ile reklam beğeni puanları arasında anlamlı bir ilişki var midır?

\section{Yöntem}

\subsection{Araştırmanın Modeli}

Gerçekleştirilen nicel, deneysel desendeki araştırma için "Ordu Üniversitesi Sosyal ve Beşeri Bilimler Etik Kurulundan" (karar no: 2021-07) 27/01/2021 tarihinde onay alınmıştır. Araştırmada katılımcılara yapılan çalışma, şartlar ve sorumlulukları hakkında bilgilendirme yapılmış ve gönüllülük formu imzalatılmıştır. Deney sırasında demografik (yaş, cinsiyet, eğitim durumu, medeni hal, gelir seviyesi) bilgileri toplanmış, deneyler, beyaza boyalı sessiz bir odada, ekrana $100 \mathrm{~cm}$ uzaklıkta rahat bir koltukta gerçekleştirilmiştir. Çalışmada katılımcılara içerisinde Türkiye'ye ait kültürel öğeler bulunan 5 adet video reklam izlettirilmiştir. Bu reklamlar izletilirken EEG cihazı aracılığı ile beyin sinyalleri toplanmıştır. Bu reklamlar gıda, otomotiv, giyim, iletişim, bankacılık sektörlerinden seçilmiştir. Video reklamların süresi 40 saniye ile 2 dakika 15 saniye arasında değişmektedir. Reklamlar katılımcılara aynı sıra ile izletilmesinde oluşabilecek etkileri ortadan kaldırmak için rastgele sıra ile izletilmiştir(Vecchiato \& Babiloni, 2011:296). Ayrıca her bir reklamın başına odaklanabilmek ve toplanan beyin sinyallerinin regülasyonu için 10 saniyelik siyah ekran eklenmiştir (Leanza, 2017:83). İzletilen reklamlardan sonra katılımcılardan reklamların beğenilerini, likert ölçeğinde (1-hiç beğenmedim, 7-çok beğendim) oylamaları istenmiştir(Leanza \& Balconi, 2017:69; Vecchiato et al., 2011:298). 


\section{2. Örneklem}

Nöropazarlama araştırmalarında gerçekleştirilen deneysel desenlerde 30 kişilik örneklem büyüklüğü çalışma için yeterli olmaktadır(Erdemir \& Yavuz, 2016:15; Sands, 2009:2). Bu çalışma sağ elini kullanan 77(29K+48E) katılımcı ile gerçekleştirilmiştir. Gönüllü katılımcılardan herhangi bir klinik psikiyatrik bir rahatsızlıklarının bulunmadığı, psikiyatrik bir ilaç kullanmadıkları, çalışmanın yapılacağı günden 24 saat önce alkol ve uyuşturucu madde kullanmadıklarını beyan ettikleri bir "katılımcı gönüllü formu" okutularak çalışmanın nasıl yapılacağı hakkında bilgi verilmiş ve çalışma onayı için imzaları alınmıştır.

Katılımcıların yaşları 18 ile 62 aralığında değişmekte olup yaş ortalaması 38'dir. Katılımcıların gelir seviyeleri ortalama 4.000-7.000 TL aralığındadır. Yaklaşık 7-10 yıl iş deneyimine sahiptir. Katılımcılar uygun örnekleme yöntemi ile seçilmiştir. Çalışma grubu gönüllülük esasına dayalı olarak araştırmacı için en ulaşılabilir olan bireylerden başlanarak oluşturulmuştur. Uygun örnekleme, araştırmacının zaman ve iş gücü kaybının aza indirilmek için ihtiyaç duyduğu büyüklükteki gruba ulaşana kadar en ulaşılabilir örnek üzerinde çalışmayı yürütmesidir(Büyüköztürk et al., 2021). Katılımcılara ilişkin demografik özellikler Tablo 1'de gösterilmektedir.

Tablo 1. Katılımcıların demografik özellikleri

\begin{tabular}{lll}
\hline Değişken & $\mathbf{N}$ & $\mathbf{\%}$ \\
\hline Cinsiyet & & 37,7 \\
$\quad$ Kadın & 29 & 62,3 \\
$\quad$ Erkek & 48 & \\
Medeni durum & 53 & 68,8 \\
$\quad$ Evli & 24 & 31,2 \\
$\quad$ Bekâr & & \\
Evdeki baskın karakter & 25 & 32,5 \\
$\quad$ Anne & 52 & 67,5 \\
Baba & & \\
Eğitim düzeyi & 21 & 27,3 \\
Lise & 14 & 18,2 \\
$\quad$ Ön Lisans & 25 & 32,4 \\
Lisans & 17 & 22,1 \\
Lisansüstü & & \\
Çocukluğun geçtiği yer & 17 & 22,1 \\
Köy & 18 & 23,4 \\
İlçe & 28 & 36,3 \\
$\quad$ Şehir & 14 & 18,2 \\
Büyükşehir & 77 & 100 \\
TOPLAM & & \\
\hline
\end{tabular}

\subsection{Veri Toplama Arac1}

Katılımcılardan demografik (yaş, cinsiyet, eğitim durumu, medeni hal, gelir seviyesi) bilgileri oluşturulan form ile toplanmıştır. Çalışmada 5 adet video reklam izlettirilmiştir. Bu reklamlar izletilirken EEG cihazı aracılığı ile beyin sinyalleri toplanmıştır. İzletilen reklamlardan sonra katılımcılardan reklamların beğenilerini, likert ölçeğinde (1-hiç beğenmedim, 7-çok beğendim) oylamaları istenmiştir(Leanza \& Balconi, 2017:69; Vecchiato et al., 2011:298).

\subsubsection{Ham EEG Verilerinin Toplanması ve Ön İşlem Uygulanması}

Gerçekleştirilen çalışmada EEG datalarının toplanması için Emotiv firmasının EPOC+ cihazı kullanılmıştır. EPOC+ cihaz1 14 kanallı(AF3,F7,F3,FC5,T7,P7,O1,O2,P8,T8,FC6,F4,F8,AF4) ve CMS/DRL(P3,P4) mastoid referans alan bir cihazdır. $256 \mathrm{~Hz}$ örnekleme frekansına sahiptir. Ham EEG dataları EmotivPRO adlı program ile toplanmıştır.

Toplanan ham EEG verileri Matlab programı üzerinde çalışan EEGLAB eklentisi üzerinde ön işleme tabi tutulmuştur(Delorme \& Makeig, 2004). Bu ön işlem sırasıyla ilk 10 saniyelik bölgenin silinmesi(sinyal 


\section{G. A. Figen - A. Tüfekçi - M. Tolon 13/3 (2021) 2819-2831}

regülasyonu için siyah ekran), 1-45Hz band geçiren filtre uygulanması, DC-OFF işlemi ile sinyal üzerindeki DC yüklerin silinmesi işlemleridir. Ardından sinyal üzerindeki mevcut artefaktların(göz kırpması, göz bebeği hareketi, kas hareketleri terleme, kalp atışı, kanal gürültüsü vb.) (Motamedi-fakhr et al., 2014:24) temizlenmesi için, "bağımsız bileşenler analizi" (ICA-indipendent component analyses) uygulanmıştır (Pion-Tonachini et al., 2019). Bağımsız bileşenler analizi ile yeni bir uzayda sinyaller üzerindeki beyin sinyalleri, artefakt, ve gürültü kaynaklarının tanımlanması sağlanmıştır. Tanımlanan bu kaynaklardan beyin sinyallerini ayrıştırmak için, otomatik aretfakt etiketleme ve silme işlemi yapan ve EEGLAB üzerinde çalışsan ADJUST eklentisi kullanılmıştır (Pion-Tonachini et al., 2019:4; Smith et al., 2017:105).

\subsubsection{Frontal Alfa Asimetrisinin Hesaplanmasi}

Temizlenen EEG verileri üzerinden kullanıcının beğenisini (hoşlanma-yaklaşma-pozitif motivasyonu) ölçümlemek için "medial frontal lop" üzerindeki F3(sol hemisfer)-F4(sağ hemisfer) dipol kanal çiftinin alfa bandındaki (8-13Hz) spektral güç asimetrisi hesaplanmıştır (Davidson, 1988; Smith et al., 2017; Vecchiato et al., 2011). Alfa dalgası osilasyonu asimetrik analizinde sol hemisferinde gerçekleşen aktivasyonun sağ hemisferde gerçekleşen aktivasyona göre da yüksek seviyede olması kişinin beğenme, pozitif motivasyon eğilimi göstermekte, tersi durumda ise kişinin beğenmeme, negatif motivasyon göstermektedir (Coan \& Allen, 2003; Davidson, 2004).

Frontal alfa asimetrisinin hesaplanması için yine MATLAB üzerinde gerçekleştirilmiştir. Bu hesaplama için fast fourier dönüşümü(FFT) uygulanarak $0.5 \mathrm{hz}$ lik aralıklarla dalga boylarına ayrıştırılmıştır. Ardından 2 saniyelik "hamming penceresi" kullanılmış ve \%75 oranında üst üste sinyallerin örtüşmesi(overlap) ile alfa(8$13 \mathrm{~Hz}$ ) bandındaki ortalama "güç spektral yoğunluğu" $\mu \mathrm{V}^{2}$ cinsinden (PSD-power spectral density)hesaplanmıştır(Smith et al., 2017:101). Çalışmada pozitif duygu yüklenimi için "beğenme", negatif duygu yüklenimi için ise "beğenmeme" ifadelerini kullanılmıştır.

$$
\text { Frontal Asimetri Değeri }=\log (P S D \text { F4) }-\log (P S D F 3)
$$

Yukarıda belirtilen formül ile frontal asimetri değeri hesaplanmıştır.

\subsection{Verilerin Analizi}

Ortalama puanları karşılaştırılacak olan örneklemler ilişkisiz olduğu için katılımcıların beğeni puanlarının demografik özelliklere göre farklılaşıp farklılaşmadığının tespitinde ilişkisiz t-testi ve Kruskal Wallis H-testi kullanılmıştır. T-testi iki grup arasında gözlenen farkın istatistiksel olarak manidar olup olmadıklarını test ederken, Kruskal Wallis ilişkisiz iki ya da daha çok örneklem ortalamasının anlamlı bir şekilde farklı olup olmadığını test etmek için uygulanır. Veriler normallik varsayımı sağlıyor olsa da grup varyansların eşitliği sağlanamadığı durumlar için one-way ANOVA'nın non-parametrik karşılığı olan Kruskal Wallis H-testi kullanılmıştır (Büyüköztürk, 2020).

Hem cinsiyet hem de evdeki baskın karakterin EEG cihazı ile ölçülen beğeni puanları arasında hem cinsiyet hem de evdeki baskın karaktere göre anlamlı bir fark olduğu görüldüğ̈̈nden gözenek ortalama puanlarını inceleyerek betimsel açıklamalarda bulunulmuştur. Oluşturulan gözeneklerden normal dağılın sergileyenler arasındaki (AK, BK ve BE) arasındaki karşılaştırmalar için t-testi kullanılırken normal dağılım sergilemeyen gözenek (AE) ile diğer gözenekler arasındaki karşılaştırmalarda non-parametrik istatistiklerden Mann Whitney U-Testi kullanılmıştır. Mann Whitney U-Testi iki ilişkisiz örneklemden elde edilen verilerden en az biri normal dağılım sergilemediği durumda t-testinin alternatifi olarak kullanılan bir testtir (Büyüköztürk et al., 2021).

Katılımcıların EEG cihazı ile ölçülen beğeni puanları ile reklam beğeni puanları arasındaki ilişkinin miktarını bulup yorumlamak amacıyla Pearson Korelasyon katsayısına bakılmıştır(Büyüköztürk et al., 2021).

\section{Bulgular}

\subsection{Katılımcıların demografik özelliklerine göre beğeni puanlarının incelenmesi}

EEG cihazı ile gerçekleştirilen ölçümlerin demografik özelliklere göre dağılımlarından oluşan veri gruplarının normallik değerleri ve grup varyanslarına ilişkin sonuçlar Tablo 2' de verilmektedir. 


$$
\text { G. A. Figen - A. Tüfekçi - M. Tolon 13/3 (2021) 2819-2831 }
$$

Tablo 2. Demografik veri gruplarının normallik değerleri ve grup varyansları

\begin{tabular}{lllll}
\hline Değişken & $\mathrm{N}$ & Çarpıklık & Basıklık & Levene's Test \\
\hline Cinsiyet & & & & \\
$\quad$ Kadın & 29 & $-0,150$ & $-0,354$ & 0,013 \\
$\quad$ Erkek & 48 & 0,563 & $-0,460$ & \\
Medeni durum & & & & \\
$\quad$ Evli & 53 & 0,350 & $-0,278$ & \\
$\quad$ Bekâr & 24 & 0,592 & $-0,326$ & \\
Evdeki baskın karakter & & & & \\
$\quad$ Anne & 25 & 0,629 & 0,158 & \\
$\quad$ Baba & 52 & $-0,273$ & $-0,902$ & \\
Eğitim düzeyi & & & & \\
$\quad$ Lise & 21 &, 217 & $-1,001$ & \\
$\quad$ Ön Lisans & 14 &,- 045 &, 134 & \\
$\quad$ Lisans & 25 &, 295 &, 5446 & \\
$\quad$ Lisansüstü & 17 &, 788 &, 735 & \\
Çocukluğun geçtiği yer & & & & \\
$\quad$ Köy & 17 & $-0,695$ & $-0,330$ & \\
$\quad$ İlçe & 18 & 0,286 & $-0,670$ & \\
$\quad$ Şehir & 28 & 0,252 & $-0,279$ & \\
$\quad$ Büyükşehir & 14 & 0,326 & $-0,883$ & \\
\end{tabular}

Tablo 2'de görüldüğü üzere tüm veriler normal dağılım sergilemektedir. Cinsiyet değişkeni dışındaki veri gruplarının varyanslarının homojen olmadığı görülmektedir. Katılımcıların EEG cihazı ile belirlenen F3-F4'e ait beğeni puanlarının demografik özelliklere göre anlamlı bir farklılık gösterip göstermediğini test etmek için ilişkisiz t-testi ve Kuruskal Wallis testi yapılmıştır (Tablo 3).

Tablo 3. Cinsiyet, medeni hal ve baskın bireye göre EEG cihazı beğeni puanlarına ilişkin t-test sonuçları

\begin{tabular}{llllllll}
\hline Değişken & & $\mathrm{N}$ & $\mathrm{X}$ & $\mathrm{S}$ & $\mathrm{Sd}$ & $\mathrm{t}$ & $\mathrm{p}$ \\
\hline \multirow{2}{*}{ Cinsiyet } & Kadın & 29 &, 9658 &, 59992 & \multirow{2}{*}{75} & \multirow{2}{*}{3,770} & 0,000 \\
Medeni & Erkek & 48 &, 5421 &, 38738 & & & \\
Hal & Evli & 53 & 0,707966 & 0,529866 & \multirow{2}{*}{46,891} & 0,161 & 0,873 \\
& Bekâr & 24 & $0,0,687725$ & 0,500881 & & & \\
Baskın & Anne & 25 &, 8822 &, 54175 & & & \multirow{2}{*}{042} \\
Birey & Baskın & & & & \multirow{2}{*}{$, 43,248$} & 2,094 & \\
& Baba & 52 &, 6148 &, 48760 & & & \\
& Baskın & & & & & & \\
\hline
\end{tabular}

Katılımcıların beğeni puanları cinsiyete göre anlamlı bir farklılık göstermektedir $(\mathrm{t}(86)=4,639 ; \mathrm{p}<0,01)$. Kadınların beğenin puanının $(X=1,161)$ erkeklerden $(X=0,55)$ anlamlı derecede yüksek olduğu görülmektedir. Katılımcıların beğeni puanı evdeki baskın karaktere göre kadınlar lehine anlamlı bir fark göstermektedir $\left(t_{(75)}=2,173 ; p<0,05\right)$. Katılımcıların beğeni puanları ise medeni duruma göre anlamlı bir farklılık göstermemektedir (değerler yazılacak). Evlilerin beğenin puanının $(X=0,754710)$ bekârların beğeni puanına $(X=0,534476)$ oldukça yakın olduğu görülmektedir.

Tablo 4.Eğitim Düzeyine göre EEG cihazı beğeni puanlarına ilişkin Kuruskal Wallis sonuçları

\begin{tabular}{llllll}
\hline Eğitim Düzeyi & $\mathrm{n}$ & Sira Ort. & sd & $\chi 2$ & $\mathrm{p}$ \\
\hline Lise & 21 & 40,05 & 3 & 1,864 &, 601 \\
Ön lisans & 14 & 43,64 & & & \\
Lisans & 25 & 39,56 & & & \\
Lisansüstü & 17 & 33,06 & & & \\
\hline
\end{tabular}




\section{G. A. Figen - A. Tüfekçi - M. Tolon 13/3 (2021) 2819-2831}

Tablo 4'de görüldüğü üzere katılımcıların beğeni puanları ile eğitim düzeyleri arasında anlamlı bir fark olmadığı görülmektedir $\chi 2(s d=3, n=77)=1,864, p>0,05$. Bir başka ifadeyle katılımcıların beğeni puanları eğitim seviyelerine göre değişmemektedir.

Tablo 5. Çocukluklarının geçtiği yere göre EEG cihazı beğeni puanlarına ilişkin Kuruskal Wallis sonuçları

\begin{tabular}{llllll}
\hline Çocukluklarının geçtiği yer & $\mathrm{n}$ & Sira Ort. & $\mathrm{sd}$ & $\chi 2$ & $\mathrm{p}$ \\
\hline Büyükşehir & 14 & 41,57 & 3 & 0,616 &, 893 \\
Şehir & 28 & 36,82 & & & \\
İlçe & 18 & 38,39 & & & \\
Köy/Kasaba & 17 & 41,12 & & & \\
\hline
\end{tabular}

Tablo $5^{\prime}$ de görüldüğü üzere katılımcıların beğeni puan ortalamaları çocukluklarının geçtiği yere göre de anlamlı bir farklılık göstermemektedir $\chi 2(\mathrm{sd}=3, \mathrm{n}=77)=0.616, \mathrm{p}>0,05$.

3.2. EEG cihazı ile ölçülen beğeni puanlarının cinsiyet ve evdeki baskın karaktere göre oluşturulan ikili gözeneklerinin incelenmesi

Katılımcıların EEG cihazı ile ölçülen beğeni puanları arasında hem cinsiyet hem de evdeki baskın karaktere göre anlamlı bir fark olduğu görüldügünden gözenek ortalama puanlarını inceleyerek betimsel açılamalarda bulunulmuştur. Hangi ikili alt grupların ortalama puanları arasında fark olduğunu belirlemek için gözenekler kodlanarak yeni değişkenler oluşturulmuştur (Tablo 6).

Tablo 6. Cinsiyet ve evdeki baskın karaktere göre 2x2'lik Matriste Gözenekler

\begin{tabular}{lll}
\hline & Kadın & Erkek \\
\hline Ana & AK & AE \\
Baba & BK & BE \\
\hline
\end{tabular}

AK: Annenin baskın karakter olduğu evdeki kadın, AE: Annenin baskın karakter olduğu evdeki erkek; BK: Babanın baskın karakter olduğu evdeki kadın; BE: Babanın baskın karakter olduğu evdeki erkek

Tablo 7. Gözeneklerin normallik değerleri

\begin{tabular}{llll}
\hline Değişken & $\mathrm{N}$ & Çarpiklık & Basılık \\
\hline AK & 15 &, 574 &,- 299 \\
& & & \\
AE & 10 & 1,251 & 2,656 \\
BK & 14 &,- 340 & $-1,084$ \\
BE & 38 &,- 268 & $-1,127$ \\
\hline
\end{tabular}

Tablo 7'de görüldüğü üzere AE gözeneğine ait veriler normal dağılım göstermemektedir. Oluşturulan gözenek ortalamalarından $\mathrm{AK}, \mathrm{BK}$ ve $\mathrm{BE}$ arasındaki karşılaştırmalarda t-testi, $\mathrm{AE}$ ile diğer gözenekler arasındaki karşılaştırmalarda Mann Whitney U-Testi Kullanılmıştır (Tablo 8).

Tablo 8. Gözenek ortalamalarına ilişkin analiz sonuçları

\begin{tabular}{llll}
\hline Gözenekler & $\mathrm{N}$ & Mean & Sig $(\mathrm{p})$ \\
\hline AK & 15 & 1,1546 & 0,001 \\
AE & 10 & 0,473654 & \\
AK & 15 & 1,1546 & 0,079 \\
BK & 14 &, 7635 & \\
AK & 15 & 1,1546 & 0,000 \\
BE & 38 & 0,560071 &, 349 \\
AE & 10 & 0,473654 & \\
BK & 14 &, 7635 &, 559 \\
AE & 10 & 0,473654 & 0,185 \\
BE & 38 & 0,560071 & \\
BK & 14 &, 7635 & \\
BE & 38 & 0,560071 & \\
\hline
\end{tabular}




\section{G. A. Figen - A. Tüfekçi - M. Tolon 13/3 (2021) 2819-2831}

Gözenekler arası çoklu karşılaştırma sonuçlarına göre, annenin baskın olduğu evdeki kadınların $(X=1,1546)$ aynı erkil yapıda yetişen erkeklerden $(X=0,473654)$ anlamlı derece daha yüksek beğeni puanına sahiptir $(\mathrm{p}<0,01)$ Fakat bu farkın babanın baskın olduğu evdeki kadınlar ile erkekler arasında bulunmadığ1 görülmektedir. Aynı zamanda annenin ya da babanın baskın olduğu bir ailede yetişen kadınların arasında da bir fark gözlenememektedir. Bu durum annenin ya da babanın baskın olduğu bir ailede yetişen erkekler için geçerlidir. Annenin baskın olduğu ortamda yetişen kadınlar ile babanın baskın olduğu ortamda yetişen erkeklerin beğeni puanı arasında anlamlı bir fark olduğu görülmektedir. Gözenekler arasındaki ortalama puan farkları ise Şekil 1'de gösterilmiştir.

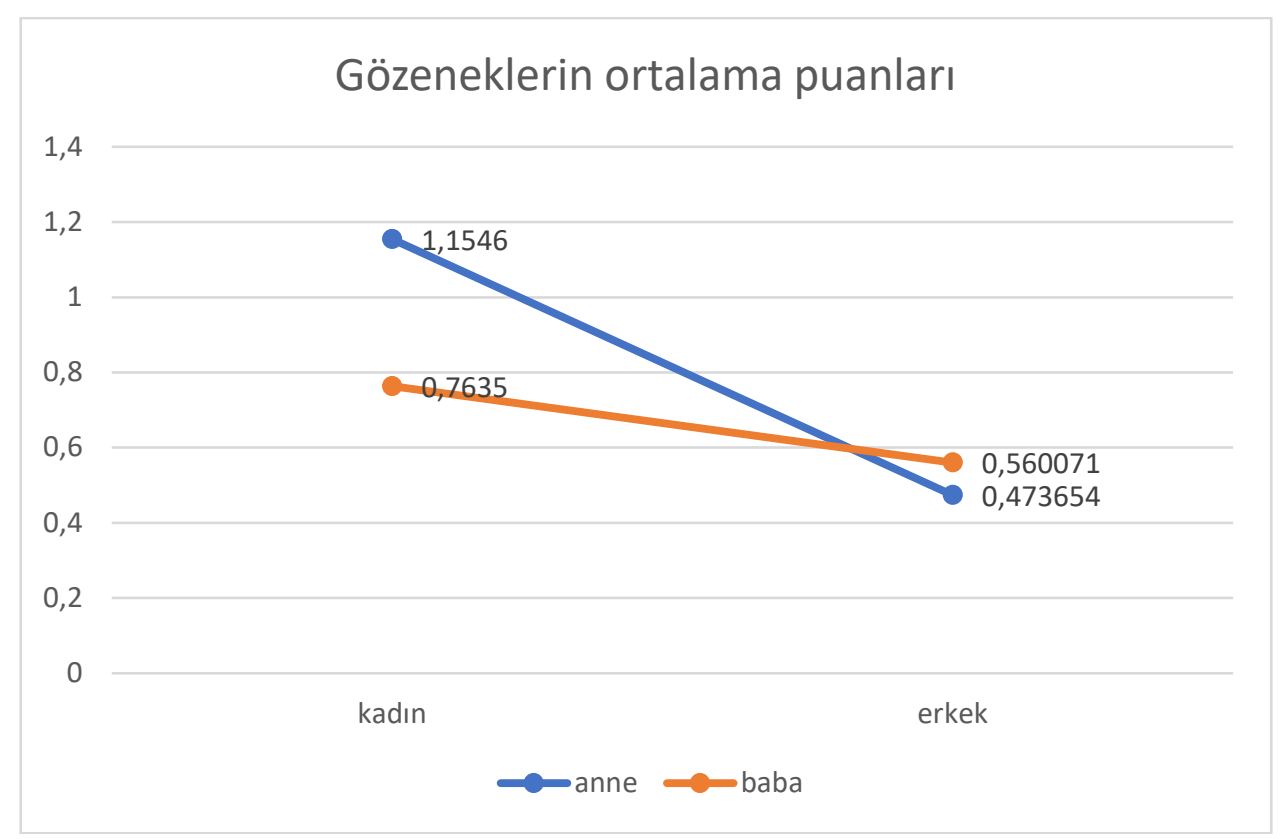

Şekil 1. Gözenekler arasındaki ortalama puanlar

3.3. EEG cihazı ile ölçülen beğeni puan ortalamaları ile reklam beğeni puan ortalamaları arasındaki ilişkinin incelenmesi

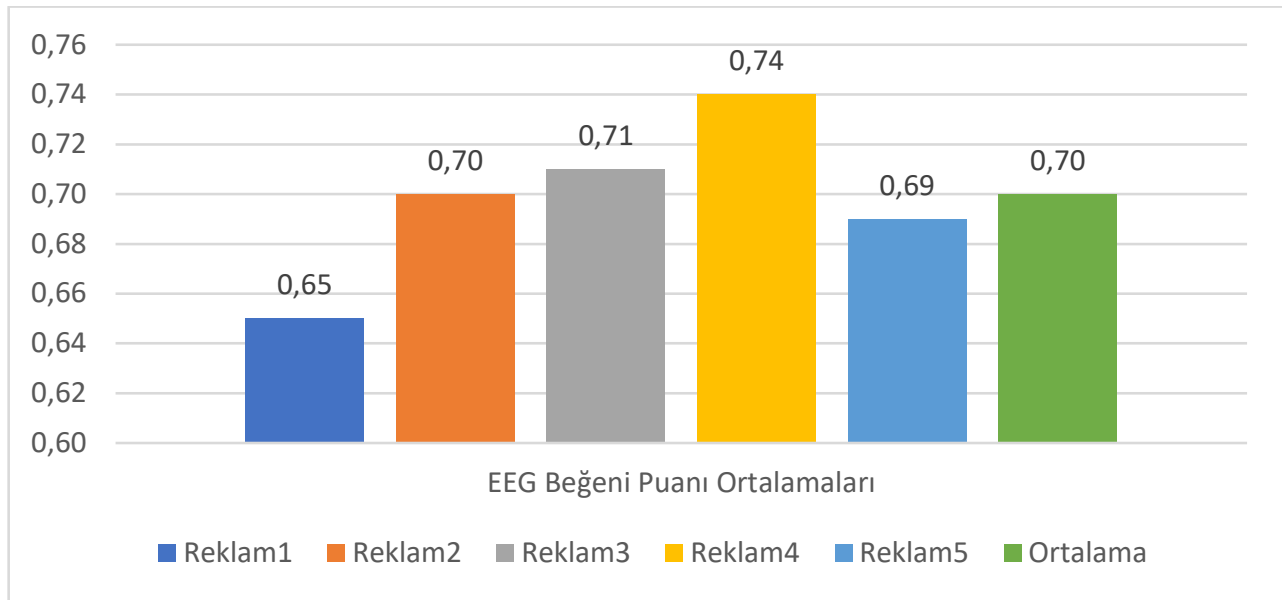

Şekil 2. EEG cihazı ile ölçülen beğeni puan ortalamaları

Şekil2'de izletilen reklamlara göre EEG beğeni puanları genel ortalamaları verilmiştir. Bu değerlere göre en yüksek değerin 0,74 ile Reklam4 ve en düşük puanın 0,65 ile Reklam1 olduğu görülmektedir. Beş reklamın EEG beğeni puanı ortalaması ise 0,70 olduğu bulunmuştur. Reklamların beğeni puanlarının pozitif değerde olması katılımcıların reklamlara karşı beğeni tutumunda olduğunu göstermektedir. 
G. A. Figen - A. Tüfekçi - M. Tolon 13/3 (2021) 2819-2831

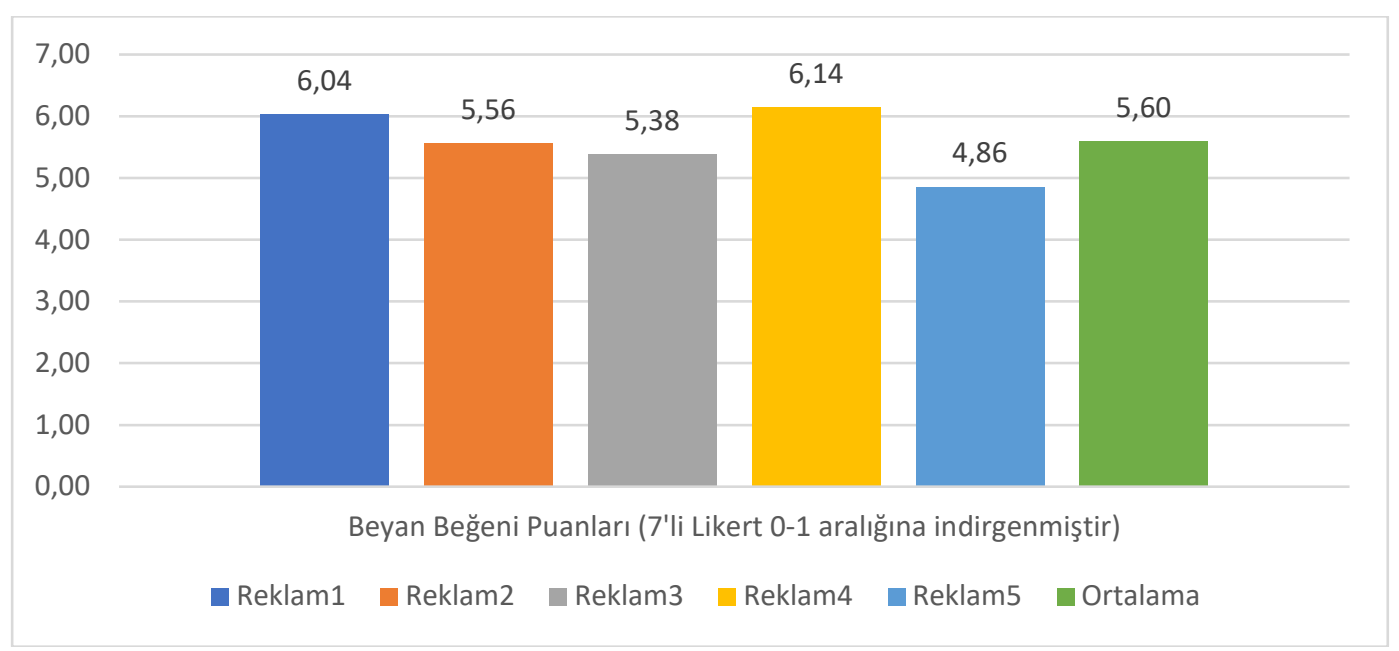

Şekil 3. Ölçek ile toplanan beyan beğeni puan ortalamaları

Şekil3'de Likert ölçeği ile reklamlara verilen değerlendirme puanlarının ortalamaları 6,14 ile en yüksek Reklam4 ve, 4,86 ile Reklam5 olduğu görülmektedir. Beş reklamın EEG beğeni puanı ortalamasının ise 5,60 olduğu bulunmuştur. Reklamların beğeni puanlarının 4 değerinin üzerinde olması katılımcıların reklamlara karşı beğeni yönünde bir tutumunun olduğunu göstermektedir.

Tablo 9 EEG cihazı ile ölçülen beğeni puan ortalamaları ve reklam beğeni puan ortalamaları normallik değerleri

\begin{tabular}{llll}
\hline & $\mathrm{N}$ & Çarpıklık & Basıklık \\
\hline Reklam beğeni puanı ortalaması (EEG) & 77 & 0.534 & 0,120 \\
Reklam beğeni puanı ortalaması (Ölçek) & 77 & -1.030 & 1,233 \\
\hline
\end{tabular}

Tablo 9'a bakıldığında katılımcıların EEG cihazı ile ölçülen beğeni puan ortalamaları ile reklam beğeni puan ortalamaları normal dağılım sergilediğinden arasındaki ilişkiyi belirlemek için Pearson korelasyon katsayısına bakılmıştır (Tablo 10).

Tablo 10. EEG cihazı ile ölçülen beğeni puan ortalamaları ile reklam beğeni puan ortalamaları arasındaki ilişki

\begin{tabular}{llll}
\hline Değişken & $\mathrm{N}$ & $\mathrm{r}$ & $\mathrm{Sig}(\mathrm{p})$ \\
\hline Reklam beğeni puanı ortalaması (EEG) & 77 & 0,205 & 0,074 \\
Reklam beğeni puanı ortalaması (Ölçek) & & & \\
\hline
\end{tabular}

Tablo 10 incelendiğinde EEG ölçümü ile katılımcıların reklam beğeni puanı $(\mathrm{r}=0,205)$ arasında düşük düzeyde $(\mathrm{r}<0,30)$ anlamlı olmayan bir ilişki olduğu görülmektedir. Bu sonuç bize neden-sonuç bağlamında bir yorum olanağı vermese de değişkenlerin birlikte hangi düzeyde olduğu konusunda fikir vermektedir. Buradan da iki değişken arasında önemli bir ilişkinin olmadığı görülmektedir.

\section{Sonuç ve Tartışma}

Kültürel öğeler içeren video reklamlara karşı ölçümlenen duygulanımların demografik özelliklere göre farklılık gösterip göstermediğinin incelendiği bu çalışmada katılımcıların beğeni yönünde tutum sergilediği görüldü. Katılımcıların EEG beğeni puan ortalamaları cinsiyete ve evdeki baskın karaktere göre anlamlı bir farklılık gösterirken aynı puanların çocukluğun geçtiği yer, medeni hal ve eğitim seviyesine göre farklılaşmadığı görüldü.

Duygusal çekiciliğin reklamlarda kullanımının tüketici tutumu üzerinde de olumlu etkisi bilinmektedir. Kültürel öğeler içeren reklamlar da, reklam çekiciliğinde kullanılan duygusal çekicilik başlığı altında yer alır (Akbari, 2015:489; Raza et al., 2018:72). Bu çalışmadaki kadınların erkeklere göre kültürel öğeler içeren reklamlarda daha çok beğeni duygusuna sahip olmasında kadınlardaki duygusal zeka ve empati gücünün daha etkin olması da bu sonucun ortaya çıkmasında etkili olmuş olabilir. Hoffmann vd.(2010:282) çalışması kadınların, yüzdeki duyguları gösteren alt ifadeleri yakalayabilmede erkeklere göre daha başarılı olduğunu göstermektedir. Yine çalışmamızı destekleyen nitelikte, duygusal çekicilik öğeleri ile tasarlanan reklamların 


\section{G. A. Figen - A. Tüfekçi - M. Tolon 13/3 (2021) 2819-2831}

kadınlarda erkeklere göre daha yüksek duygulanım etkisi oluşturduğu görülmüştür (Muralidharan \& Sheehan, 2018:10). Vecchiato vd. (2013:41) EEG cihazı ile frontal alfa asimetrisi yöntemini kullanarak yapmış olduğu çalışmada da kadınların video reklamlardaki duygulanımlarının ve ilgilerinin erkeklere göre daha yüksek olduğunu bulmuştur. Alan yazındaki bu çalışmalar, bu çalışmada ortaya konulan, kadınların erkeklere göre kültürel öğeler içeren reklamlarda daha çok beğeni duygusuna sahip olduğu bulgusunu desteklemektedir.

Baskın karakterin anne olduğu anaerkil evlerde büyüyen katılımcıların, baskın karakterin baba olduğu ataerkil evlerde büyüyen katılımcılara göre kültürel öğeler taşıyan reklamları daha çok beğendiği görülmüştür. Hem cinsiyet hem de evdeki baskın karakter bağlamında beğeni puanlarının kadınlar lehine daha yüksek olduğu görülmüştür. Anaerkil ortamda yetişen kadınlar, anaerkil ortamda yetişen erkeklerden ve ataerkil ortamda yetişen erkeklerden daha yüksek beğeni göstermektedir. Çift ve Canan'a (2017) göre evrimsel olarak kadınların konuşamayan bebeğin bakımı sırasında, yüz ifadesi ve davranışlarından bebeğin istek ve ihtiyaçlarını anlayabilmesi, kadınları duygular analizinde erkeklerden daha başarılı kılmaktadır. Aynı zamanda bebek bakımının kadınların ayna nöron sistemlerini geliştirdiği, empati ve duygulanım seviyesini yükselttiği ileri sürülmüştür. Bu durum, kadınların reklam gibi uyaranlar karşısında duygusal seviyelerin yüksek olduğunu ve yetiştirdikleri çocuklara duygusallıklarını aktardığını göstermektedir. Chung'un (2017:47) yapmış olduğu çalışmasında ortaya koyduğu anaerkil ortamda büyüyen kadınların kültürel değerleri koruduğu ve duygusal yüklenimlerinin daha yüksek olduğu bulgusu da bu çalışmada ki sonucu desteklemektedir. Kiel ve Kalomiris (2015:14) kültür kavramının, ebeveynlerin duygusal sosyal ilişkilerini ve davranışlarını etkilediğini ve ebeveynlilerin bu kültür kavramını çocuğun duygusal tanım ve düzenlemelerine aktarıldığını belirtmiştir.

Ayrıca bu çalışmada katılımcıların EEG beğeni puanlarının katılımcıların çocukluğunun geçtiği yer, medeni hal ve eğitim seviyesine göre farklılaşmadığı görülmüştür. Subhankar ve Anand(2019:380) çevrimiçi reklamlar üzerinde yapmış olduğu çalışmada da eğitim düzeyinin reklamlara karşı ilgilenimi ve satın alma davranışını etkilemediğini bulgusunu desteklemiştir. Erigüç vd.(2014:406) yapmış olduğu çalışmada duygulanımların çocukluğun geçtiği yere göre bir farklılık göstermediğini ortaya koymuştur.

Ayrıca çalışmada kültürel öğeler taşıyan video reklamları izleyen katılımcılardan ölçek yoluyla toplanan beğeni puan ortalaması ile EEG üzerinden toplanan beyin sinyallerden frontal alfa asimetri yöntemi ile hesaplanan beğeni puan ortalamaları arasında anlamlı bir ilişki bulunmadığı görülmüştür. "Sosyal istenirlik eğilimi" kavramı kişilerin anket ve ölçek gibi geleneksel yöntemlerle toplanan verilerin her zaman, tam anlamıyla doğruluğu yansıtmayacağını ve kişinin sosyal uyum sağlama veya tercihlerini gizleme yöneliminde olabileceğini göstermektedir (Grimm, 2010). Bu tutarsızlıklar aynı zamanda kişilerin yaş, cinsiyet, etnik kimlik gibi demografik özelliklerinden de kaynaklanabilmektedir (Larson, 2019). Katılımcıların hem beğeni puanları hem de EEG beğeni puanları olumlu olmasına karşın aralarında anlamlı bir ilişki bulunamamıştır. Gözlemlenen bu durumun katılımcıların kültürel öğelere karşı toplumsal değer yargılarını ön planda tutarak, toplumsal uyum yönünde bir eğilim göstermesinden kaynaklandığ1 söylenebilir. Türk toplumunun kollektivist toplum yapısı da bu sonucun çıkmasında etkili olmuş olabilir. Lim'in (2016:4) çalışması da bireysel toplumdaki duygusal tepkilerin, kollektivist toplumdaki duygusal tepkilere göre daha güçlü ve açık bir şekilde ifade edildiğini göstermektedir.

Sonuç olarak bu çalışmada kültürel öğeler içeren video reklamların, aynı kültürde büyümüş bireyler üzerinde olumlu izlenim bıraktığını görüldü. Çalışmada karşımıza çıkan en çarpıcı sonuç kadın cinsiyetinin ve anaerkil ortamda yetişmenin kültürel öğelere karşı duygulanımları güçlendirdiğidir. Bu araştırmada, pazarlama çalışmalarında kültür öğelerinin kullanımının önemli olduğu görülürken, özellikle hedef kitlesi kadın ağırlıklı ve anaerkil olan bireylerde daha etkin bir şekilde kültür öğelerinden faydalanılması gerektiği sonucu çıkmaktadır. Diğer bir sonuç ise kişilerin beğeni durumları hakkındaki beyanlarının gerçeği yansıtmadığının görülmüş olmasıdır. Bu da nöropazarlama araçlarının bireyin tercih ve kararlarını objektif olarak ortaya koymadığı durumlarda etkin bir pazarlama araştırma aracı olarak kullanılması gerektiğini ortaya koymaktadır.

Kültür yaşayan bir olgu ve reklam çekiciliği üzerinde etkili bir öğe olsa da reklamlarında kültürü dönüştürme/değiştirme etkisinin olduğu unutulmamalıdır (Czarnecka et al., 2018:14). Kültür kavramı dinamik olduğundan bu konuda tekrarlanacak olan çalışmalar hem değişen kültürü gözlemlemek hem de 


\section{G. A. Figen - A. Tüfekçi - M. Tolon 13/3 (2021) 2819-2831}

toplumun kültür değerleri kullanılan uyaranlara karşı verdiği duygulanımları takip etmek açısından önemlidir. Yine farklı kültür özelliği taşıyan toplumlar üzerinde yapılacak çalışmalarda elde edilecek bulgular, hem insan duygulanımlarıyla ilgilenen disiplinler hem de reklamcıların etkili kampanyalar yapabilmesi açısından önem arz etmektedir.

$\mathrm{Bu}$ çalışmada beş farklı sektörden seçilen ve kültürel öğeler taşıyan reklamlar kullanılmış olup ileride yapılacak çalışmalarda kültürel öğeler taşıyan reklamların seçilecek bir sektör üzerindeki etkinliği yahut markanın ya da ürünün akılda kalıcılığı ve satın alma kararına etkisi araştırılabilir. Ayrıca kültür pazarlaması ile ön plana çıkmak isteyen kentlerin tanıtım çalışmalarının hangi kültür faktörü ile ön planda tutulması gerektiği araştııılabilir. Yine bu çalışmada reklamların genel duygulanım ortalamaları üzerinden hareket edilmiş olup sahne bazlı duygulanımlar üzerinden hangi kültür öğelerinin daha etkili olduğu da ayrıca araştırılabilir. Bu çalışmanın sonuçları reklamlarda kullanılacak kültürel öğelerin hangi hedef tüketici grubuna uygulanacağı ve oluşturulacak yeni reklam kampanyaların etkinliğinin artırılması adına katkı sağlayacağı düşünülmektedir.

\section{Kaynakça}

Akbari, M. (2015). Different Impacts of Advertising Appeals on Advertising Attitude for High and Low Involvement Products. Global Business Review, 16(3), 478-493.

Batı, U., \& Erdem, O. (2015). Ben Bilmem Beynim Bilir! MediaCat Kitapları.

Bočková, K., Škrabánková, J., \& Hanák, M. (2021). Theory and practice of neuromarketing: Analyzing human behavior in relation to markets. Emerging Science Journal, 5(1), 44-56.

Braeutigam, S., Rose, S. P. R., Swithenby, S. J., \& Ambler, T. (2004). The distributed neuronal systems supporting choice-making in real-life situations: Differences between men and women when choosing groceries detected using magnetoencephalography. European Journal of Neuroscience, 20(1), 293-302.

Büyüköztürk, Ş. (2020). Sosyal Bilimler İçin Veri Analizi El Kitabı İstatistik, Araştırma Deseni SPSS Uygulamaları ve Yorum (28th ed.). Pegem Akademi Yayıncilık.

Büyüköztürk, Ş., Çakmak, E. K., Akgün, Ö. E., Karadeniz, Ş., \& Demirel, F. (2021). Eğitimde Bilimsel Araştırma Yöntemleri. In Pegem Akademi (30th ed.). Pegem Akademi Yayıncılık.

Chung, A. Y. (2017). Behind the Myth of the Matriarch and the Flagbearer: How Korean and Chinese American Sons and Daughters Negotiate Gender, Family, and Emotions. Sociological Forum, 32(1), 28-49.

Çift, P., \& Canan, S. (2017). Beynin Sırları (1.baskı). Destek Yayınları.

Coan, J. A., \& Allen, J. J. B. (2003). Frontal EEG asymmetry and the behavioral activation and inhibition system. 40, 106-114.

Czarnecka, B., Brennan, R., \& Keles, S. (2018). Cultural Meaning, Advertising, and National Culture: A FourCountry Study. Journal of Global Marketing, 31(1), 4-17.

Damasio, A. R. (1994). Descartes' error. Avon Books.

Davidson, R. J. (1988). EEG Measures of Cerebral Asymmetry: Conceptual and Methodological Issues. International Journal of Neuroscience, 39(1-2), 71-89.

Davidson, R. J. (2004). What does the prefrontal cortex " do " in affect : perspectives on frontal EEG asymmetry research. $67,219-233$.

de Mooij, M. (2015). Cross-cultural research in international marketing: clearing up some of the confusion. International Marketing Review, 32(6), 646-662.

Delorme, A., \& Makeig, S. (2004). EEGLAB: an open source toolbox for analysis of single-trial EEG dynamics including independent component analysis. Journal of Neuroscience Methods, 13, 9-21.

Eagleman, D., \& Brandt, A. (2017). The runaway species: How human creativity remakes the world. Catapult. 


\section{G. A. Figen - A. Tüfekçi - M. Tolon 13/3 (2021) 2819-2831}

Erdemir, K. O., \& Yavuz, Ö. (2016). Nöropazarlama'ya Giriş (S. E. GÜLÜM (ed.); 1st ed.). BrandMap.

Erigüç, G., Eriş, H., \& Kabalcıŏlu, F. (2014). Emotional Intelligence and Communication Skills of Nursing Students: Example of Harran University School of Health. International Online Journal of Educational Sciences, 6(2), 398-412.

Eser, Z., Kurtulmusoglu, B., \& Tolon, M. (2011). Perceptions of marketing academics, neurologists, and marketing professionals about neuromarketing. Journal of Marketing Management, 27, 854-868.

Grimm, P. (2010). Social Desirability Bias. Wiley International Encyclopedia of Marketing, 1999, 2010.

Hoffmann, H., Kessler, H., Eppel, T., Rukavina, S., \& Traue, H. C. (2010). Expression intensity, gender and facial emotion recognition: Women recognize only subtle facial emotions better than men. Acta Psychologica, 135(3), 278-283.

Jovanovic, P., Vlastelica, T., \& Cicvaric Kostic, S. (2016). Impact of Advertising Appeals on Purchase Intention. Management: Journal of Sustainable Business and Management Solutions in Emerging Economies, 21(81), 3545.

Khurana, V., Gahalawat, M., Kumar, P., Roy, P. P., Dogra, D. P., Scheme, E., \& Soleymani, M. (2021). A Survey on Neuromarketing using EEG Signals. IEEE Transactions on Cognitive and Developmental Systems, 8920(c).

Kiel, E. J., \& Kalomiris, A. E. (2015). Current themes in understanding children's emotion regulation as developing from within the parent-child relationship. In Current Opinion in Psychology (Vol. 3, pp. 1116). Elsevier.

Lakhan, P., Banluesombatkul, N., Changniam, V., Dhithijaiyratn, R., Leelaarporn, P., Boonchieng, E., Hompoonsup, S., \& Wilaiprasitporn, T. (2019). ConsLakhan, P., Banluesombatkul, N., Changniam, V., Dhithijaiyratn, R., Leelaarporn, P., Boonchieng, E., Hompoonsup, S., \& Wilaiprasitporn, T. (2019). Consumer grade brain sensing for emotion recognition. IEEE Sensors Journal, 19(21), 9896-9907. https://d. IEEE Sensors Journal, 19(21), 9896-9907.

Larson, R. B. (2019). Controlling social desirability bias. International Journal of Market Research, 61(5), 534-547.

Leanza, F. (2017). Consumer neuroscience: The traditional and VR TV commercial. Neuropsychological Trends, 21(1), 81-90.

Leanza, F., \& Balconi, M. (2017). TV commercial and rTMS : can brain lateralization give us information about consumer preference? Neuropsychological Trends, 21, 65-80.

Lim, N. (2016). Cultural differences in emotion: differences in emotional arousal level between the East and the West. Integrative Medicine Research, 5(2), 105-109.

Matsumoto, D., \& Hwang, H. S. (2012). Culture and emotion: The integration of biological and cultural contributions. Journal of Cross-Cultural Psychology, 43(1), 91-118.

Motamedi-fakhr, S., Moshrefi-torbati, M., Hill, M., Hill, C. M., \& White, P. R. (2014). Signal processing techniques applied to human sleep EEG signals - a review Biomedical Signal Processing and Control Signal processing techniques applied to human sleep EEG signals - A review. Biomedical Signal Processing and Control, 10(June), 21-33.

Muralidharan, S., \& Sheehan, K. (2018). The role of guilt in influencing sustainable pro-environmental behaviors among shoppers: Differences in response by gender to messaging about england's plastic-bag levy. Journal of Advertising Research, 58(3), 349-362.

Ortony, A., \& Turner, T. J. (1990). What's basic about basic emotions? Psychological Review, 97(3), 315-331.

Özkara, B. Y. (2017). Nöropazarlamada Elektroensefalografi(EEG) Kullanımı. Ekin Basım Yayın Dağıtım.

Ozkara, B. Y., \& Bagozzi, R. (2021). The use of event related potentials brain methods in the study of Conscious and unconscious consumer decision making processes. Journal of Retailing and Consumer Services, 58(August 2020), 102202.

Pion-Tonachini, L., Kreutz-Delgado, K., \& Makeig, S. (2019). The ICLabel dataset of electroencephalographic 


\section{G. A. Figen - A. Tüfekçi - M. Tolon 13/3 (2021) 2819-2831}

(EEG) independent component (IC) features. Data in Brief, 25, 104101.

Plantinga, J., \& Trehub, S. E. (2014). Revisiting the innate preference for consonance. Journal of Experimental Psychology: Human Perception and Performance, 40(1), 40-49.

Rampersad, G., \& Althiyabi, T. (2020). Fake news: Acceptance by demographics and culture on social media. Journal of Information Technology and Politics, 17(1), 1-11.

Raza, S. H., Abu Bakar, H., \& Mohamad, B. (2018). Advertising appeals and Malaysian culture norms. Journal of Asian Pacific Communication, 28(1), 61-82.

Sands, S. F. (2009). Sample Size Analysis for Brainwave Collection (EEG) Methodologies.

Smith, E. E., Reznik, S. J., Stewart, J. L., \& Allen, J. J. B. (2017). Assessing and conceptualizing frontal EEG asymmetry: An updated primer on recording, processing, analyzing, and interpreting frontal alpha asymmetry. International Journal of Psychophysiology, 111, 98-114.

Subhankar, D., \& Anand, N. (2019). Digital sustainability in social media innovation: a microscopic analysis of Instagram advertising $\mathcal{E}$ its demographic reflection for buying activity with R. 81(Mtde), 377-382.

Tooby, J., \& Cosmides, L. (2008). The evolutionary psychology of the emotions and their relationship to internal regulatory variables. In Handbook of emotions, 3rd ed. (pp. 114-137). The Guilford Press.

Vecchiato, G., \& Babiloni, F. (2011). Neurophysiological measurements of memorization and pleasantness in neuromarketing experiments. Communication and Enactment, 6800 LNCS, 294-308.

Vecchiato, G., Cherubino, P., Trettel, A., \& Babiloni, F. (2013). Neuroelectrical Brain Imaging Tools for the Study of the Efficacy of TV Advertising Stimuli and their Application to Neuromarketing. In Neuroelectrical Brain Imaging Tools for the Study of the Efficacy of TV Advertising Stimuli and their Application to Neuromarketing. Springer Heidelberg.

Vecchiato, G., Toppi, J., Astolfi, L., De Vico Fallani, F., Cincotti, F., Mattia, D., Bez, F., \& Babiloni, F. (2011). Spectral EEG frontal asymmetries correlate with the experienced pleasantness of TV commercial advertisements. Medical and Biological Engineering and Computing, 49(5), 579-583. 